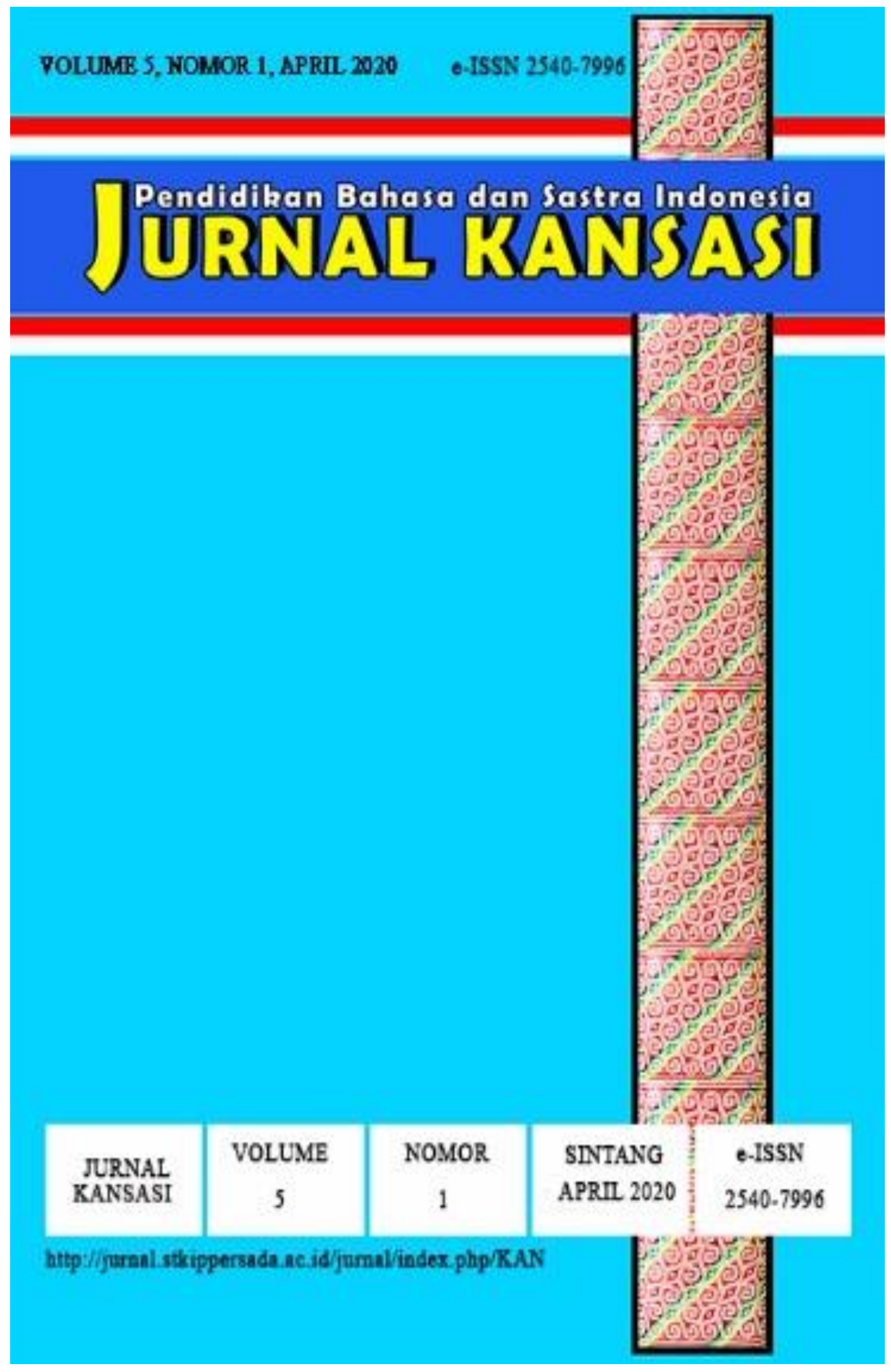




\section{JURNAL KANSASI \\ Volume 5, Nomor 1, April 2020}

Jurnal online pendidikan bahasa dan sastra Indonesia terbit dua kali setahun yaitu pada bulan April dan Oktober. Berisi tulisan yang diangkat dari hasil telaah dan penelitian di bidang pendidikan, bahasa, dan sastra Indonesia.

\section{Editor In Chief}

Debora Korining Tyas

\section{Deputy Chief Editor}

Sri Astuti

\section{Editor}

Tedi Suryadi

Ursula Dwi Oktaviani

Yudita Susanti

Muhammad Thamimi

Muchammad Djarot

\section{Reviewer}

Yusuf Olang

Herpanus

Bani Sudardi

Yoseph Yapi Taum

Agus Wartiningsih

\section{Administratative Staffs \\ Valentinus Ola Beding \\ Evi Fitrianingrum}

Alamat Redkasi: Program Studi Pendidikan Bahasa dan Sastra Indonesia STKIP Persada Khatulistiwa Sintang, Jl. Pertamina Sengkuang, Kotak Pos 126, Hp/WA. 082150544710.

Website e-journal KANSASI: http://jurnal.stkippersada.ac.id/jurnal/index.php/KAN

Jurnal ilmiah online KASASI diterbitkan oleh Program Studi Pendidikan Bahasa dan Sastra Indonesia STKIP Persada Khatulistiwa Sintang. Terbit sejak April 2016.

Penyunting menerima tulisan ilmiah yang belum pernah diterbitkan dimedia lain, baik cetak maupun elektronik. Naskah diketik untuk ukuran HVS A4 dengan spasi satu koma lima, maksimal 20 halaman. Tulisan yang masuk direview dan selanjutnya untuk diterbitkan. 


\section{JURNAL KANSASI \\ Volume 5, Nomor 1, April 2020}

\section{DAFTAR ISI}

Halaman

Hubungan Kemandirian Belajar Terhadap Hasil Belajar Siswa pada Mata Pelajaran Bahasa Indonesia Kelas VIII $1-8$

SMP N 02 Tempunak

\section{Herpanus, Evi Fitria Ningrum, Ahensius Bantut}

STKIP Persada Khatulistiwa Sintang

Analisis Kesulitan Membaca Permulaan pada Sub Tema Tugasku

Sebagai Umat Beragama pada Siswa Kelas II SD Negeri 06

Setapang Laut Ketungau Hilir

Ursula Dwi Oktaviani, Gabriel Serani, Etikustini

STKIP Persada Khatulistiwa Sintang

Analisis Struktural Kumpulan Cerita Rakyat

Dayak Jangkang Tanjung

Valentinus Ola Beding, Tedi Suaryadi, Frideta Heni

STKIP Persada Khatulistiwa Sintang

Peningkatan Keterampilan Menulis Karangan Deskripsi

Menggunakan Media Miniatur (Maket)

Debora Korining Tyas, Sudarto, Ahmad Ridho Inoviar

STKIP Persada Khatulistiwa Sintang

Hubungan Kebiasaan Menulis dengan Kemampuan Menulis Cerpen pada Siswa Kelas XI Sekolah Menengah Atas

Nusantara Indah Sintang

Yusuf Olang, Evi Fitrianingrum, Markulanus Alex

$55-63$

STKIP Persada Khatulistiwa Sintang

Peningkatan Hasil Belajar Siswa Menggunakan

Metode Talking Stick pada Pembelajaran Tematik

Tedi Suryadi, Meranti Sintauli Tampubolon

$64-70$

STKIP Persada Khatulistiwa Sintang

Peningkatan Penguasaan Kosakata Bahasa Indonesia

Menggunakan Media Gambar pada Siswa Kelas 1

Sekolah Dasar Negeri 43 Tapang Aceh Tahun Ajaran 2019/2020

$71-80$

Gabriel Serani, Ilinawati, Lidia Heni

STKIP Persada Khatulistiwa Sintang 
Hubungan Hasil Belajar Siswa Dengan Kemampuan

Menerapkan Nilai-Nilai Pancasila

Agnesia Hartini, Lukas Robinson

$81-91$

STKIP Persada Khatulistiwa Sintang

Proses Dan Makna Simbol Ritual Munjong Dayak Tobag

Yudita Susanti, Yusuf Olang, Marselina Risca

$92-98$

STKIP Persada Khatulistiwa Sintang

Penerapan Pendekatan Eksploratory Discovery untuk Meningkatkan

Motivasi dan Hasil Belajar Kognitif

Sirilus Sirhi, Hendrikus Julung, Valentina Suci Susanti

$99-112$

STKIP Persada Khatulistiwa Sintang

Analisis Makna Bahasa Promosi Katalog Oriflame

Edisi Bulan Januari-Maret Tahun 2019

$113-126$

Ursula Dwi Oktaviani, Debora Korining Tyas, Ira Winarti

STKIP Persada Khatulistiwa Sintang

Peran Guru Pkn dalam Membina Civic Skill Siswa

Sekolah Menengah Pertama Negeri 7

Agnesia Hartini, Simon Petrus

$127-137$

STKIP Persada Khatulistiwa Sintang 
Vol. 5, No. 1, April 2020

e-ISSN: 2540-7996

http://jurnal.stkippersada.ac.id/jurnal/index.php/KAN/index

\title{
HUBUNGAN KEMANDIRIAN BELAJAR TERHADAP HASIL BELAJAR SISWA PADA MATA PELAJARAN BAHASA INDONESIA KELAS VIII SMP N O2 TEMPUNAK
}

\author{
Herpanus $^{1}$, Evi Fitrianingrum ${ }^{2}$, Ahensius Bantut ${ }^{3}$ \\ ${ }^{1}$ STKIP Persada Khatulistiwa, ${ }^{2}$ STKIP Persada Khatulistiwa, \\ ${ }^{3}$ STKIP Persada Khatulistiwa, \\ e-mail: herpanus2003@yahoo.co.id ${ }^{1}$, fitrianingrumevi250@gmail.com ${ }^{2}$ \\ ahenintelejen345@gmail.com ${ }^{3}$
}

Diajukan, 4 Februari 2020, Diterima, 4 Maret 2020, Dterbitkan, 1 April 2020

\begin{abstract}
ABSTRAK
Masalah dalam penelitian ini adalah apakah terdapat hubungan antar kemandirian belajar terhadap hasil belajar siswa pada mata pelajaran Bahasa indonesia kelas VIII. Penelitian ini bertujuan untuk mengetahui (1) seberapa besar hubungan kemandirian belajar terhadap hasil belajar, (2) seberapa besar pengaruh kemandirian belajar terhadap hasil belajar, (3) apakah terdapat hubungan yang signifikan antara kemandirian belajar terhadap hasil belajar. Pendekatan yang digunakan dalam penelitian ini adalah kuantitatif. Jumlah populasi dalam penelitian ini adalah 81 siswa dan seluruh populasi dijadikan sebagai sampel. Data yang diambil menggunakan kuesioner. Penelitian ini menggunakan pendekatan penelitian kuantitatif, metode penelitian inferensial dan bentuk penelitian korelasi. Populasi sebanyak 81 dan semua populasi dijadikan sebagai sampel penelitian, sedangkan teknik pengumpul data yang digunakan yaitu teknik komunikasi tidak langsung dan teknik dokumentasi. Alat pengumpul data berupa angket menggunakan skala likert dan dokumen. Selanjutnya terlebih dahulu dilakukan uji validitas dan reliabilitas data kemudian pengujian asumsi klasik. Data penelitian selanjutnya dianalisis dengan uji kontribusi yaitu uji korelasi sederhana, uji determinasi, dan uji regresi. Berdasarkan tujuan penelitian, hasil penelitian menunjukkan bahwa (1) kemandirian belajar terhadap hasil belajar memiliki hubungan sebesar 0,350 dalam kategori rendah. (2) pengaruh kemandirian belajar terhadap hasil belajar sebesar 13,8\%. (3) terdapat pengaruh yang signifikan bersifat positif dan masuk dalam kriteria hubungan rendah. Dari hasil penelitian di atas, peneliti memberikan saran kepada siswa agar menyadari pentingnya kemandirian belajar yang berasal dari internal siswa itu sendiri tanpa ada dorongan atau paksaan dari orang lain serta meningkatkan kemandirian belajar baik di rumah, di kelas dan di sekolah sehingga mampu pula meningkatkan hasil belajar siswa yang baik.
\end{abstract}

Kata kunci: Kemandirian Belajar, Hasil Belajar. 
Vol. 5, No. 1, April 2020

e-ISSN: 2540-7996

http://jurnal.stkippersada.ac.id/jurnal/index.php/KAN/index

ABSTRACT
The problem in this study is whether there is a relationship of learning independence to student learning outcomes in Indonesian VIII grade subjects. This study aims to find out ((1) how extent the relationship of learning independence to learning outcomes, (2) how much is the effect of learning independence on learning outcomes, (3) is there a significant relationship between learning independence of learning outcomes.The number of population in this study was 81 students and the entire population was sampled. The data was gained by questionnaire.The approach of this research is quantitative, the method of the research is inferential research and inthe form of correlation.The number of population in this study was 81 students and the entire population was sampled. While the data collection techniques used are indirect communication techniques and documentation.The data instrument collection are questionnaires using a Likert scale and documents. After testing the validity and reliability of the data then testing of classic assumption. Then the data was analyzed with contribution test namely simple correlation, determination test and regression test. Based on the research objectives, the results of the study show that (1) learning independence of learning outcomes has a relationship of 0.350 in the low category. (2) the effect of learning independence on learning outcomes is 13.8\%. (3) There is significant influence namely Positive and positive relationships with low category.From the results of the above research, researcher provide advice to students in order to understand the independence of learning that comes from the internal students themselves without the help or coercion from others and to increase the independence of learning well at home, in class and at school can help improve student learning outcomes well.

Keyword: Learning Independence and Learning Outcomes. 
Vol. 5, No. 1, April 2020

e-ISSN: 2540-7996

http://jurnal.stkippersada.ac.id/jurnal/index.php/KAN/index

PENDAHULUAN

Pendidikan memiliki peranan penting dalam perkembangan pembangunan suatu negara. Pendidikan mengemban tugas untuk menghasilkan generasi muda penerus bangsa yang unggul dalam kepribadian, pemikiran dan karya sebagai sumber daya manusia yang berkualitas sehingga mampu menjadi tonggak bangsa dan negara. Jadi, pendidikan merupakan wahana untuk meningkatkan dan mengembangkan kualitas sumber daya manusia. Pendidikan tentu saja terdiri dari guru dan siswa, dimana guru sebagai tenaga pendidik dan siswa sebagai peserta didik yang harus memiliki kemampuan dalam mengembangkan potensi dirinya tanpa batas. Oleh sebab itu siswa dituntut memiliki peran aktif dalam proses pembelajaran baik di luar sekolah atau pun di dalam sekolah, dengan kata lain siswa harus memiliki kesadaran tentang kemandirian belajar tanpa harus bergantung kepada orang lain.

Pembelajaran berpusat pada siswa tidak membatasi siswa untuk memperoleh pengetahuan hanya dari guru. Sebaliknya, mereka dibatasi oleh kemampuan mereka sendiri tentang kapan dan bagaimana mereka akan belajar. Saat ini, sekolah bergerak maju dengan menggunakan pendekatan yang berpusat pada siswa. Dengan pendekatan ini, siswa lebih aktif terlibat dalam materi pelajaran, mereka lebih termotivasi sebagai peserta didik dan mereka belajar keterampilan lebih banyak terutama disiplin, komunikasi, dan kolaborasi kemampuan. Jadi, kemandirian seseorang dalam belajar akan menetukan arah belajar dan prestasi belajar seseorang. Kemandirian yang dimiliki siswa diharapkan dapat memanfaatkan waktu sekolah dan di rumah menggunakan keseluruhan sumber belajar baik sumber belajar tercetak maupun sumber belajar lainnya. Manfaat kemandirian menurut Abdullah (Fathoni, 2015: 28-29) yaitu menumbuhkan kesadaran dan tanggung jawab yang lebih besar dalam membuat pelajaran menjadi bermakna terhadap dirinya sendiri, menumbuhkan rasa lebih penasaran untuk mencoba hal-hal baru, dan siswa akan memandang permasalahan sebagai tantangan yang baru dihadapi, minat belajar terus berkembang dan pembelajaran lebih menyenangkan dan mereka menjadi lebih termotivasi dan gigih, mandiri, disiplin diri, percaya diri dan berorientasi pada tujuan.

Kemandirian dapat diartikan sebagai sikap (perilaku) dan mental yang memungkinkan seseorang untuk bertindak bebas, benar, dan bermanfaat; berusaha melakukan segala sesuatu dengan jujur dan benar atas dorongan dirinya sendiri dan kemampuan mengatur diri sendiri, sesuai dengan hak dan kewajibannya, sehingga dapat menyelesaikan masalah-masalah yang dihadapinya serta bertanggung jawab terhadap segala keputusan yang telah diambilnya melalui berbagai pertimbangan sebelumnya. Sedangkan pengertian belajar diartikan sebagai suatu 
Vol. 5, No. 1, April 2020

e-ISSN: 2540-7996

http://jurnal.stkippersada.ac.id/jurnal/index.php/KAN/index

proses usaha yang dilakukan individu untuk memperoleh suatu perubahan perilaku yang baru secara keseluruhan, sebagai hasil dari pengalaman individu itu sendiri dalam interaksi individu dengan lingkungannya.

Dari pengertian di atas maka dapat disimpulkan bahwa kemandirian belajar adalah kondisi aktifitas belajar yang mandiri dan tidak tergantung pada orang lain, memiliki kemauan, berinisiatif serta bertanggung jawab sendiri dalam menyelesaikan masalah belajarnya. Kemandirian belajar siswa akan terwujud apa bila siswa aktif mengontrol sendiri segala sesuatu yang dikerjakan, mengevaluasi dan selanjutnya merencanakan segala sesuatu yang berkaitan dengan pembelajaran yang dilalui dan siswa juga mau aktif dalam proses pembelajaran. Belajar merupakan proses penting bagi perubahan perilaku setiap orang dan belajar itu mencakup segala sesuatu yang dipikirkan dan dikerjakan oleh seseorang. Menurut Gagne (Susanto, 2016:1) memberikan dua definisi dalam masalah belajar, yaitu: (1) Belajar ialah suatu proses di mana suatu organisme berubah perilakunya sebagai akibat pengalaman. (2) Belajar adalah suatu proses untuk memperoleh motivasi dalam pengetahuan, keterampilan, kebiasaan, dan tingkah laku. Adapun menurut Burton (Susanto, 2016: 3), belajar dapat diartikan sebagai perubahan tingkah laku pada diri individu berkat adanya interaksi antara individu dengan individu lain dan individu dengan lingkungannya sehingga mereka lebih mampu berinteraksi dengan lingkungannya. Dari penjelasan dan definisi beberapa ahli di atas, maka dapat disimpulkan bahwa belajar merupakan suatu aktivitas yang dilakukan seseorang dengan sengaja dalam keadaan sadar untuk memperoleh suatu konsep, pemahaman, atau pengetahuan baru sehingga memungkinkan seseorang terjadinya perubahan perilaku yang relatif tetap baik dalam berpikir, merasa, maupun dalam bertindak. Untuk mengetahui seberapa jauh perubahan yang terjadi perlu adanya penilaian. Hasil dari penilaian inilah yang disebut hasil belajar. Menurut Sudjana (2014: 3) hasil belajar siswa adalah perubahan tingkah laku seperti bidang kognitif, afektif, dan psikomotoris. Adapun menurut K. Brahim (dalam Susanto, 2016: 5), hasil belajar merupakan tingkat keberhasilan siswa dalam mempelajari materi pelajaran di sekolah yang dinyatakan dalam skor yang diperoleh dari hasil tes mengenai sejumlah materi pelajaran tertentu. Sedangkan menurut Susanto sendiri (2016: 5) bahwa hasil belajar merupakan perubahan-perubahan yang terjadi pada diri siswa, baik yang menyangkut aspek kognitif, afektif, dan psikomotor sebagai hasil dari kegiatan belajar.

Berhubungan dengan penjelasan di atas, penulis merasa tertarik untuk mengetahui lebih lanjut tentang "Hubungan Kemandirian Belajar Terhadap Hasil Belajar Siswa pada Mata Pelajaran Bahasa Indonesia kelas VIII SMP Negeri 02 Tempunak Tahun Pelajaran 2019/2020”. 
Vol. 5, No. 1, April 2020

e-ISSN: 2540-7996

http://jurnal.stkippersada.ac.id/jurnal/index.php/KAN/index

Alasan khusus peneliti memilih judul penelitian ini yang pertama, berdasarkan informasi yang didapat dari guru bahwa belum pernah mahasiswa yang ingin meneliti tentang kemandirian belajar siswa terhadap hasil belajar, padahal kemandirian belajar sangat dekat dengan perilaku dan sikap terhadap siswa sebagai pelajar, sehingga kemandirian belajar sering kali terabaikan dan bahkan tidak menyadari bahwa pentingnya kemandirian belajar. Alasan yang kedua, setelah siswa menjawab angket pertanyaan kemandirian belajar, siswa mengetahui apa saja butir-butir kemandirian belajar yang berkaitan dengan kehidupan sehari -hari di sekolah. Alasan ketiga, agar dapat memotivasi siswa untuk lebih giat belajar dengan terus meningkatkan motivasi belajarnya supaya hasil belajar juga meningkat. Penelitian ini nantinya diharapkan dapat menunjukkan bahwa kemandirian belajar memiliki hubungan yang erat dengan hasil belajar, sehingga dapat menambah wawasan dan pengetahuan serta memberi acuan bagi guru untuk dapat mengubah pola dan sikap mengajar, dari hanya sebagai pengajar (pemberi informasi) berubah menjadi fasilitator dan mediator yang baik dalam proses pembelajaran dengan memperhatikan kemandirian belajar siswa

\section{METODE PENELITIAN}

Penelitian lapangan dilaksanakan di SMP N 02 Tempunak yang menghabiskan waktu kurang lebih tiga hari yaitu dari tanggal 20-23 November 2019. Penelitian ini menfokuskan pada hubungan variabel bebas terhadap variebal terikat. Pendekatan penelitian ini menggunakan pendekatan kuantitatif. Menurut Badri $(2012,12)$ penelitian dengan pendekatan kuantitatif menekankan analisisnya pada data-data numerikal (angka-angka) yang diolah dengan metode statistik. Pada dasarnya pendekatan kuantitatif dilakukan pada jenis penelitian inferensial dan menyandarkan kesimpulan hasil penelitian pada suatu probabilitas kesalahan penolakan nihil. Dengan metode kuantitatif akan diperoleh signifikansi perbedaan kelompok atau signifikansi hubungan antar variabel yang diteliti. Pada umumnya penelitian kuantitatif merupakan penelitian dengan jumlah sampel besar. Metode yang digunakan dalam penelitian ini adalah metode penelitian inferensial, menurut Badri (2012: 13) penelitian inferensial merupakan penelitian dengan melakukan analisis hubungan antar variabel dengan pengujian hipotesisi. Dengan demikian, kesimpulan penelitian jauh melebihi sajian data kuantitatif saja dan kesimpulannya adakala bersifat umum. Sedangkan bentuk penelitiannya yaitu penelitian korelasi (correlation researh), menurut Badri (2012: 16) tujuan penelitian korelasi adalah untuk mendeteksi sejauh mana varian-varian pada suatu vaktor berhubungan dengan variasivariasi pada satu atau lebih faktor lain berdasarkan pada koefisien korelasi. Biasanya peneliti tidak memanipulasi keadaan variabel yang ada dan langsung mencari keberadaan hubungan serta tingkat hubungan variabel yang direfleksikan dalam koefisien korelasi.

Dalam penelitian ini, populasi penelitian berjumlah 81 siswa kelas VIII A, B dan kelas C. Kelas A berjumlah 29 siswa yang terdiri dari 14 siswa laki-laki dan 15 siswa perempuan. Kelas B berjumlah 28 siswa yang terdiri dari 14 siswa laki-laki dan 14 siswa perempuan. 
Vol. 5, No. 1, April 2020

e-ISSN: 2540-7996

http://jurnal.stkippersada.ac.id/jurnal/index.php/KAN/index

Sedangkan kelas $\mathrm{C}$ berjumlah 24 siswa yang terdiri dari 10 siswa laki-laki dan 14 siswa perempuan.

Tabel 1 Jumlah Populasi

\begin{tabular}{|c|c|c|c|}
\hline \multirow[b]{2}{*}{ Kelas } & \multicolumn{2}{|c|}{ Jenis Kelamin } & \multirow[b]{2}{*}{$\begin{array}{c}\text { Jumlah } \\
\text { Siswa }\end{array}$} \\
\hline & $\begin{array}{c}\text { Laki- } \\
\text { laki }\end{array}$ & $\begin{array}{c}\text { Perempua } \\
\text { n }\end{array}$ & \\
\hline VIII A & 14 & 15 & 29 \\
\hline VIII B & 14 & 14 & 28 \\
\hline VIII C & 10 & 14 & 24 \\
\hline $\begin{array}{c}\text { Jumlah } \\
\text { Siswa }\end{array}$ & 38 & 43 & 81 \\
\hline
\end{tabular}

Teknik pengambilan sampel yang digunakan dalam penelitian ini adalah teknik sampling jenuh. Menurut Sugiyono (2017: 124) sampling jenuh adalah teknik penentuan sampel bila semua anggota populasi digunakan sebagai sampel. Menurut Sugiyono (2015: 68) makin besar jumlah sampel mendekati populasi, maka peluang kesalahan generalisasi makin kecil dan sebaliknya, makin kecil jumlah sampel menjauhi populasi, maka makin besar kesalahan generalisai (diberlalukan umum). Teknik pengumpul data yang digunakan dalam penelitian ini yaitu teknik komunikasi tidak langsung dan teknik dokumentasi. Pada teknik komunikasi tidak langsung menggunakan angket atau kuesioner. Menurut Sugiyono (2017: 199) kuesioner merupakan teknik pengumpulan data yang dilakukan dengan cara memberi seperangkat pertanyaan atau pernyataan tertulis kepada responden untuk dijawabnya. Angket digunakan untuk mendapatkan data tentang kemandirian belajar siswa. Selain teknik komunikasi tidak langsung, teknik lain yaitu

Tabel 2 Hasil Uji Korelasi Spearman

\begin{tabular}{|c|c|c|c|c|}
\hline & & & $\begin{array}{l}\text { Kemandiri } \\
\text { an_Belajar }\end{array}$ & $\begin{array}{l}\text { Hasil_- } \\
\text { Belajar }\end{array}$ \\
\hline \multirow[t]{6}{*}{$\begin{array}{l}\text { Spearma } \\
\text { n's rho }\end{array}$} & \multirow[t]{3}{*}{$\begin{array}{l}\text { Kemandiri } \\
\text { an_Belajar }\end{array}$} & $\begin{array}{l}\text { Correlation } \\
\text { Coefficient }\end{array}$ & 1,000 &, $350^{* *}$ \\
\hline & & Sig. (2-tailed) & &, 001 \\
\hline & & $\mathrm{N}$ & 81 & 81 \\
\hline & \multirow[t]{3}{*}{$\begin{array}{l}\text { Hasil_Bela } \\
\text { jar }\end{array}$} & $\begin{array}{l}\text { Correlation } \\
\text { Coefficient }\end{array}$ &, $350^{* *}$ & 1,000 \\
\hline & & Sig. (2-tailed) &, 001 & \\
\hline & & $\mathrm{N}$ & 81 & 81 \\
\hline
\end{tabular}

teknik dokumentasi. Menurut Badri (2012: 35) menyatakan bahwa teknik dokumentasi yaitu teknik mengambil data dengan memeriksa dokumen-dokumen yang telah ada sebelum penelitian berlangsung. Dokumen dalam penelitian ini adalah data nilai mid, data nama siswa, dan daftar absensi. Pada penelitian ini, metode dokumentasi digunakan untuk mengetahui prestasi belajar yang berupa nilai prestasi siswa yang terdiri dari nilai mid semester ganjil. 
Vol. 5, No. 1, April 2020

e-ISSN: 2540-7996

http://jurnal.stkippersada.ac.id/jurnal/index.php/KAN/index

Sebelum angket kemandirian belajar digunakan dalam penelitian, terlebih dahulu dilakukan pengujian validitas dan reliabilitas. Uji prasyarat analisis menggunakan uji normalitas, linearitas dan uji homogenitas. Analisis data yang digunakan yaitu analisis perhitungan koefisien korelasi spearman, koefisien determinasi dan uji regresi.

PEMBAHASAN (Times New Roman, 12, Spasi 1.5, Justify, Bold)

\section{Hasil Penelitian}

Berdasarkan hasil pengujian analisis, maka diperoleh hasil penelitian sebagai berikut:

a. Besar hubungan kemandirian belajar terhadap hasil belajar siswa kelas VIII SMP N 02 Tempunak tahun pelajaran 2019/2020. Berdasarkan hasil analisis koefisien korelasi spearman, diperoleh nilai hubungan kemandirian belajar terhadap hasil belajar sebesar 0,350 yang termasuk dalam kategori hubungan rendah bersifat positif.

Tabel 3. Hasil Uji Koefisien

Determinasi (Model Summary)

\begin{tabular}{|c|c|c|c|c|}
\hline $\begin{array}{l}\text { Mo } \\
\text { del }\end{array}$ & $\mathrm{R}$ & $\begin{array}{c}\mathrm{R} \\
\text { Square }\end{array}$ & $\begin{array}{c}\text { Adjusted R } \\
\text { Square }\end{array}$ & $\begin{array}{l}\text { Std. Error of } \\
\text { the Estimate }\end{array}$ \\
\hline 1 & $\begin{array}{r}, 37 \\
2^{a}\end{array}$ & ,138 & ,127 & 11,921 \\
\hline
\end{tabular}

b. Besar pengaruh kemandirian belajar terhadap hasil belajar siswa kelas VIII SMP N 02 Tempunak tahun pelajaran 2019/2020. Berdasarkan hasil analisis koefisien determinasi, diperoleh nilai pengaruh variable (kemandirian belajar) terhadap variabel Y (hasil belajar) sebesar 0,138 atau 13,8\%.

c. Hubungan yang signifikan kemandirian belajar terhadap hasil belajar siswa kelas VIII SMP N 02 Tempunak tahun pelajaran 2019/2020. Berdasarkan hasil pengujian koefisien korelasi spearman, dan berdasarkan konsep dasar pengambilan keputusan bahwa apabila nilai signifikansi $<0,05$, maka terdapat hubungan yang signifikan kemandirian belajar erhadap hasil belajar. Dari hasil olah menggunakan aplikasi SPSS didapat nilai sig 0,001 $<0,05$ yang menandakan bahwa terdapat hubungan yang signifikan.

Berdasarkan hasil perhitungan yang telah dikemukakan di atas, diketahui adanya hubungan yang saling berkaitan antara kemandirian belajar dengan hasil belajar Bahasa Indonesia. Oleh karena itu, individu yang memiliki kemandirian belajar yang tinggi dalam proses kegiatan belajar Bahasa Indonesia akan lebih cenderung memiliki intensitas proses belajar Bahasa Indonesia yang tinggi. Adapun tujuan yang akan dicapai oleh individu tersebut yaitu hasil dari belajar Bahasa Indonesia itu sendiri. Kemandirian merupakan suatu hal yang memiliki peran penting dalam pembelajaran khususnya pembelajaran Bahasa Indonesia. Hal ini karena kemandirian belajar merupakan kemampuan siswa untuk melakukan kegiatan 
Vol. 5, No. 1, April 2020

e-ISSN: 2540-7996

http://jurnal.stkippersada.ac.id/jurnal/index.php/KAN/index

belajar dengan dorongan diri sendiri dan tanpa paksaan atau dorongan orang lain dan didorong oleh kemauan sendiri, pilihan sendiri, dan disertai rasa tanggung jawab.

\section{SIMPULAN}

Hasil penelitian ini menunjukan bahwa terdapat pengaruh positif dan signifikan kemandirian belajar terhadap hasil belajar Bahasa Indonesia Siswa kelas VIII SMP 02 Tempunak Tahun Pelajaran 2019/2020. Berdasarkan hasil penelitian tentang hubungan antara kemandirian belajar terhadap hasil belajar siswa pada mata pelajaran Bahasa Indonesia kelas VIII SMP Negeri 02 Tempunak tahun pelajaran 2019/2020, peneliti akan membuat kesimpulan berdasarkan tujuan penelitian yaitu besar hubungan kemandirian belajar terhadap hasil belajar mata pelajaran Bahasa Indonesia di kelas VIII sebesar 0,350 yang dikategorikan sebagai hubungan yang rendah. Pengaruh kemandirian belajar terhadap hasil belajar pada mata pelajaran Bahasa Indonesia sebesar 13,8\%. Terdapat hubungan yang signifikan antara kemandirian belajar terhadap hasil belajar, hal ini dibuktikan dengan dasar pengambilan apabila nilai signifikansi $<0,05$ maka dinyatakan hubungan tersebut signifikan yaitu didapatkan nilai sebesar $0,001<0,05$.

Namun demikian, kemandirian belajar bukan satu-satunya faktor yang menyebabkan meningkatnya hasil belajar siswa. Tetapi terdapat faktor lain yag mempengaruhi tinggi rendahnya hasil belajar siswa baik faktor internal maupun eksternal seperti motivasi, sarana dan prasarana, disiplin, lingkungan sekolah, lingkungan keluarga, lingkungan masyarakat, guru dan lainnya.

\section{DAFTAR PUSTAKA}

Badri, Sutrisno. 2012. Metode Statistika Untuk Penelitian Kuantitatif. Yogyakarta: Ombak Dua

Fathoni, Aziiz. 2015. Pengaruh Perhatian Orang Tua, Kemandirian Belajar Dan Fasilitas Belajar Terhadap Prestasi Belajar Ekonomi Akuntansi Siswa Kelas XI IPS Di SMA N 2 Rembang Tahun Ajaran 2014/201. Skripsi:Universitas Negeri Semarang.

Sudjana, Nana. 2014. Penilaian Hasil Proses Belajar Mengajar. Bandung: PT REMAJA ROSDAKARYA.

Sugiyono. 2015. Statistika Untuk Penelitian. Bandung: Alfabeta.

2017. Metode Penelitian Pendidikan Pendekatan Kuantitatif, Kualitatif, dan R\&D. Bandung: Alfabeta

Susanto, Ahmad. 2013. Teori Belajar \& Pembelajaran Di sekolah Dasar. Jakarta: KENCANA. 


\section{Petunjuk Bagi (Calon) Penulis Jurnal KANSASI}

1. Artikel yang ditulis untuk Jurnal KANSASI adalah hasil telaah dan hasil penelitian dibidang pendidikan, bahasa, dan sastra Indonesia serta tidak pernah diterbitkan dimedia lain, baik cetak maupun elektronik.

2. Naskah diketik dengan huruf Times New Romans, ukuran 12, dengan spasi 1,5, menggunakan kertas A4, margin atas, kiri, kanan dan bawah $2.54 \mathrm{~cm}$, dengan maksimum 20 halaman, dan diserahkan secara online melalui laman (http://jurnal.stkippersada.ac.id/jurnal/index.php/KAN) pada bagian submission, dan terlebih dahulu penulis melakukan registrasi sebagai penulis (author). Pada saat diserahkan, file dalam format $p d f$.

3. Nama penulis artikel dicantumkan tanpa gelar akademik dan di tempatkan di bawah judul artikel. Nama penulis hendaknya dilengkapi dengan alamat lembaga tempat penelitian serta alamat korespondensi. Bila naskah ditulis oleh tim, maka penyunting hanya berhubungan dengan penulis utama.

4. Artikel ditulis dalam bahasa Indonesia dengan format esai, disertakan judul masingmasing bagian artikel. Judul artikel dicetak dengan huruf kapital dengan posisi tengah atas dengan ukuran huruf 14 serta ditebalkan.

5. Sistematika artikel hasil telaah adalah: judul, nama penulis (tanpa gelar), identitas lembaga, alamat e-mail, abstrak (maksimum 250 kata), kata kunci, pendahuluan; pembahasan, simpulan, dan daftar pustaka.

6. Sistematika artikel hasil penelitian adalah: judul, nama penulis (tanpa gelar), abstrak (maksimum 250 kata), pendahuluan, metode penelitian, pembahasan, simpulan, dan daftar pustaka.

7. Sumber rujukan minmal terbitan sepuluh tahun terkahir. Rujukan yang diutamakan adalah sumber-sumber primer berupa laporan penelitian, atau artikel penelitian terbitan jurnal ilmiah.

8. Perujukan, pengutipan, tabel, dan gambar menggunakan ketentuan yang ada pada template penulisan artikel ilmiah pada Jurnal KANSASI.

9. Naskah diketik sesuai dengan tata bahasa baku bahasa Indonesia.

10. Setiap naskah ditelaah oleh penyunting ahli (reviewer) yang ditunjuk oleh penyunting sesuai dengan bidang kepakaran. Penulis artikel diberi kesempatan untuk merivisi naskah berdasrkan rekomendasi dari penyunting. Pemuatan atau penolakan naskah akan diberitahukan secara online melalui e-mail.

11. Penyuntingan naskah pra-terbit dikerjakan oleh penyunting (editor). Naskah pra-terbit dapat batal diterbitkan apabila diketahui bermasalah.

12. Segala sesuatu yang menyangkut perizinan atau penggunaan software computer untuk pembuatan naskah atau hal lain yang terkait dengan pelanggaran hak cipta yang dilakukan oleh penulis, serta konsekuensi hukum yang mungkin timbul karenanya, sepenuhnya menjadi tanggungjawab penulis. 